\title{
Erratum: Chemoselective conversion of biologically sourced polyols into chiral synthons
}

Laura L. Adduci, Trandon A. Bender, Jennifer A. Dabrowski and Michel R. Gagné

Nature Chemistry 7, 576-581 (2015); published online 23 June 2015; corrected after print 11 August 2015.

In the original graphical abstract for this Article, an in-house error meant that an incorrect intermediate was shown; this has now been corrected in the online versions, and should have appeared as shown below.
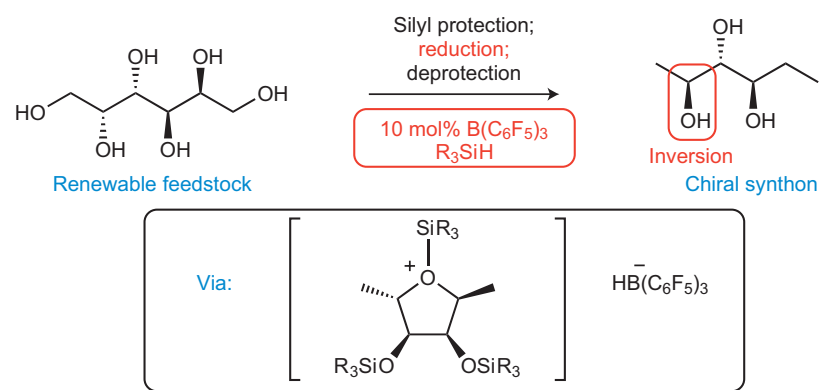